SHORT REPORT

\title{
Array based CGH and FISH fail to confirm duplication of 8p22-p23.1 in association with Kabuki syndrome
} J D Hoffman, Y Zhang, J Greshock, K L Ciprero, B S Emanuel, E H Zackai, B L Weber, J E Ming

J Med Genet 2005;42:49-53. doi: 10.1136/img.2004.024372

Background: Kabuki (Niikawa-Kuroki) syndrome comprises a characteristic facial appearance, cleft palate, congenital heart disease, and developmental delay. Various cytogenetically visible chromosomal rearrangements have been reported in single cases, but the molecular genetic basis of the condition has not been established. A recent report described a duplication of $8 p 22-p 23.1$ in 13/13 patients.

Objective: To determine the frequency of an $8 p$ duplication in a cohort of patients with Kabuki syndrome.

Methods: An 8p duplication was sought using two independent methods-array based comparative genomic hybridisation (aCGH) and fluorescence in situ hybridisation (FISH)in 15 patients with a definitive clinical diagnosis of Kabuki syndrome.

Results: No evidence for a duplication of $8 p$ was obtained by $\mathrm{FISH}$ or aCGH in any of the 15 patients.

Conclusions: 8p22-p23.1 duplication may not be a common mechanism for Kabuki syndrome. Another genetic abnormality may be responsible for the aetiology in many patients.

K abuki syndrome, or Niikawa-Kuroki syndrome, comprises a characteristic facial appearance, short stature, skeletal anomalies, dermatoglyphic abnormalities, and mental retardation. ${ }^{12}$ Congenital heart disease, cleft palate, dental anomalies, and involvement of other organ systems may occur. Characteristic facial features include long palpebral fissures with eversion of the lower lids, prominent eyelashes, lateral thinning of the eyebrows, and prominent auricles. Persistent fetal fingertip pads are also commonly present. Elucidation of the molecular genetic cause of this condition has been hampered by a relative lack of familial instances or consistent chromosomal abnormalities. ${ }^{3}$ Recently, metaphase comparative genomic hybridisation (CGH) and fluorescence in situ hybridisation (FISH) have been used to detect an interstitial tandem duplication ranging between 0.83 and 3.5 megabases in chromosome region 8 p22-p23.1 in a panel of patients with Kabuki syndrome. ${ }^{45}$ However, the frequency of this abnormality in the syndrome has not been clearly established. In this report, we assess for the 8p22-p23.1 duplication in a cohort of 15 subjects with a definite clinical diagnosis of Kabuki syndrome.

\section{METHODS \\ Patients}

All 15 subjects were evaluated in the clinical genetics centre at The Children's Hospital of Philadelphia by two of us (EHZ and JEM). The diagnosis of Kabuki syndrome was based on facial features including long eyelashes, eversion of the lower lateral eyelid, anomalous eyebrows, and a depressed nasal tip (fig 1). Three of the subjects have been described in previous clinical reports. ${ }^{67}$ Patients provided informed consent upon enrolment in the study, which was approved by the Institutional Review Board of The Children's Hospital of Philadelphia. Signed permission to reproduce the photographs shown in fig 1 was given by the parents. All subjects had a normal karyotype (at the 500 band level or higher) and a normal subtelomeric FISH study carried out as part of the clinical evaluation. Seven subjects were male and eight were female; two were of latino ancestry and the remainder were white.

A lymphoblastoid cell line (No GM14485) from a patient who did not have Kabuki syndrome and who had an inverted duplication-deletion of $8 \mathrm{p}$ was obtained from the Coriell Institute for Medical Research (Camden, New Jersey, USA). The karyotype was 46,XY,del $\operatorname{dup}(8)($ qter $\rightarrow$ p23.1::p23.1 $\rightarrow$ p11.2). This sample was used as a positive control for the $8 \mathrm{p}$ duplication (clone RP11-31B7).

\section{Fluorescence in situ hybridisation analysis}

Bacterial artificial chromosome (BAC) clones were obtained from the BACPAC Resource (Oakland, California, USA) and end sequenced to verify their identity at the nucleic acid/ protein core facility at The Children's Hospital of Philadelphia. FISH analysis was carried out as described previously. ${ }^{8}$ BACs were isolated using the Pefectprep plasmid kit (Eppendorf, Hamburg, Germany) and probes labelled with Spectrum Red or Green (Vysis Inc, Downers Grove, Illinois, USA) by nick translation. Both metaphase and interphase spreads were prepared either from peripheral blood lymphocytes or lymphoblastoid cell lines using standard methodology. Chromosomes were visualised by counterstaining with DAPI.

\section{Array based comparative genomic hybridisation}

The array based comparative genomic hybridisation (aCGH) array that we employed includes a set of 4134 BAC clones spanning the human genome at approximately a 0.92 megabase resolution. ${ }^{9}$ Genomic DNA was isolated using standard methods. Test genomic DNA was labelled with random hexamers and $\mathrm{Cy} 3$ labelled dUTP. Pooled normal control DNA was labelled with Cy5 labelled dUTP. Dual colour hybridisation was carried out and data were acquired using an Affymetrix 428 laser scanner. Data from each fluorophore were combined and the composite image imported into GenePix Pro 4.0 (Axon Instruments, Sunnyvale, California, USA). The raw fluorescence data were used to calculate a ratio for each clone (indicating the relative DNA copy number in the test sample compared with the reference sample). As an additional control, each experiment was repeated after reciprocal labelling of the samples by swapping the labelling dyes.

Abbreviations: aCGH, array based comparative genomic hybridisation; BAC, bacterial artificial chromosome; FISH, fluorescence in situ hybridisation 

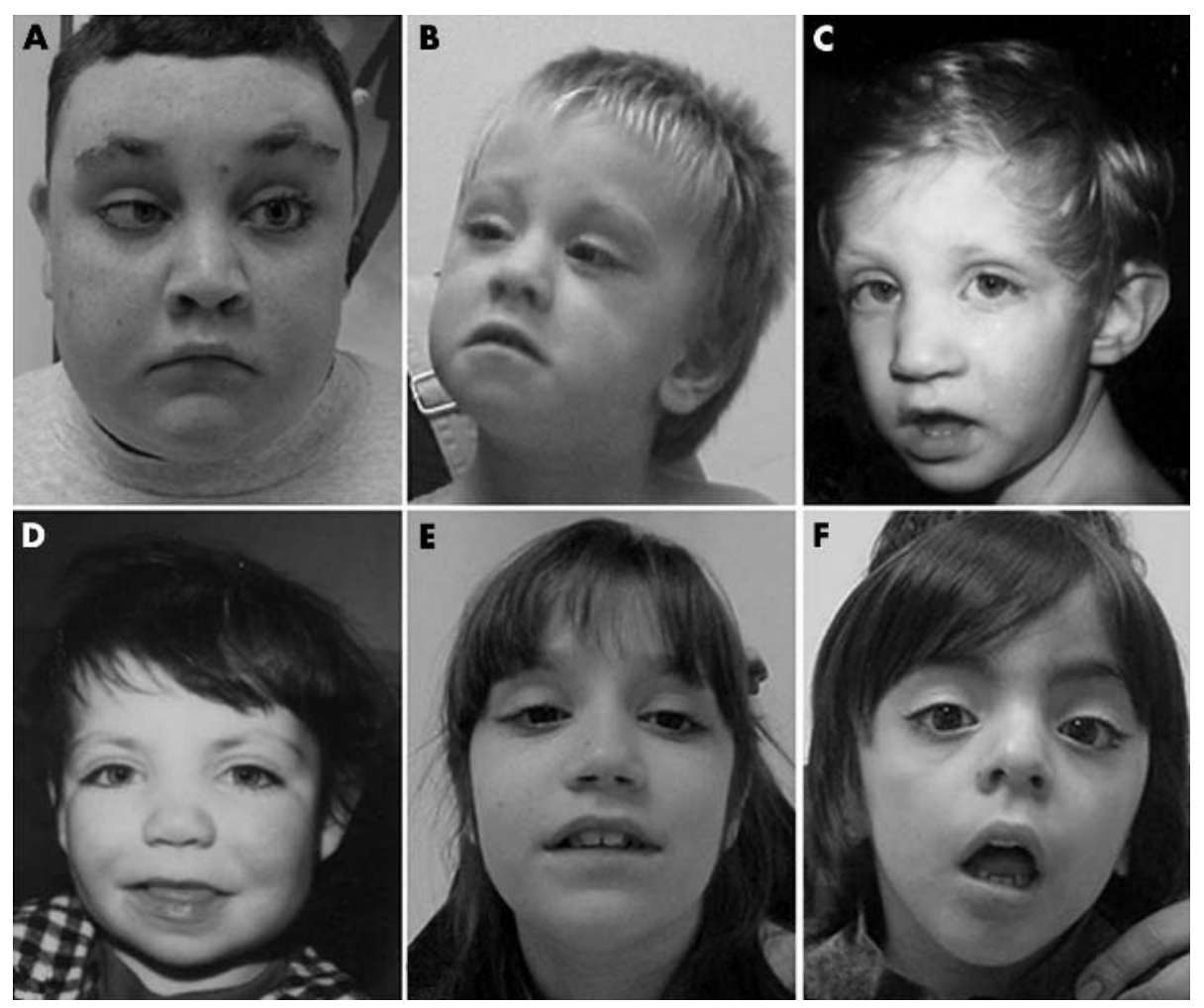

Figure 1 Representative subjects with Kabuki syndrome studied in this report. (A) Patient 1. (B) Patient 2. (C) Patient 3. (D) Patient 5. (E) Patient 8. (F) Patient 10. Permission to reproduce these photographs was given by the parents.

\section{RESULTS}

\section{BAC selection}

The report of the $8 \mathrm{p}$ duplication ${ }^{4}$ described a duplication of BAC clones mapping to the region between 10.04 and 12.99 megabases $(\mathrm{Mb})$ on chromosome $8 \mathrm{p}$ (genome position as per Genome Browser, University of California, Santa Cruz (UCSC), genome.ucsc.edu, July 2003 freeze) (fig 2). We selected four of these BAC clones mapping to the 8p22-p23.1 duplication region for FISH analysis: RP11-252K12, RP11235I5, RP11-80B8, and RP11-31B7 (table 1, fig 2). These four clones map within a $1.9 \mathrm{Mb}$ region on chromosome 8p22p23.1. In addition, BAC RPIl-122N1l was noted to show three signals in interphase analysis in the report of the $8 \mathrm{p}$ duplication. ${ }^{4}$ This BAC was also analysed in our patient cohort.
Table 1 BAC clones mapping to 8p22-8p23.1 used for analysis

\begin{tabular}{ll}
\hline BAC & Base position (Mb) \\
\hline RP11-252K12 & $10.89-11.07$ \\
RP11-23515 & $11.54-11.72$ \\
RP11-297K5 & $11.57-11.74$ \\
RP11-80B8 & $11.62-11.80$ \\
RP1 1-31B7 & $12.75-12.78$ \\
\hline
\end{tabular}

Base position from UCSC Genome Browser (July 2003 freeze) (http://genome.ucsc.edu).

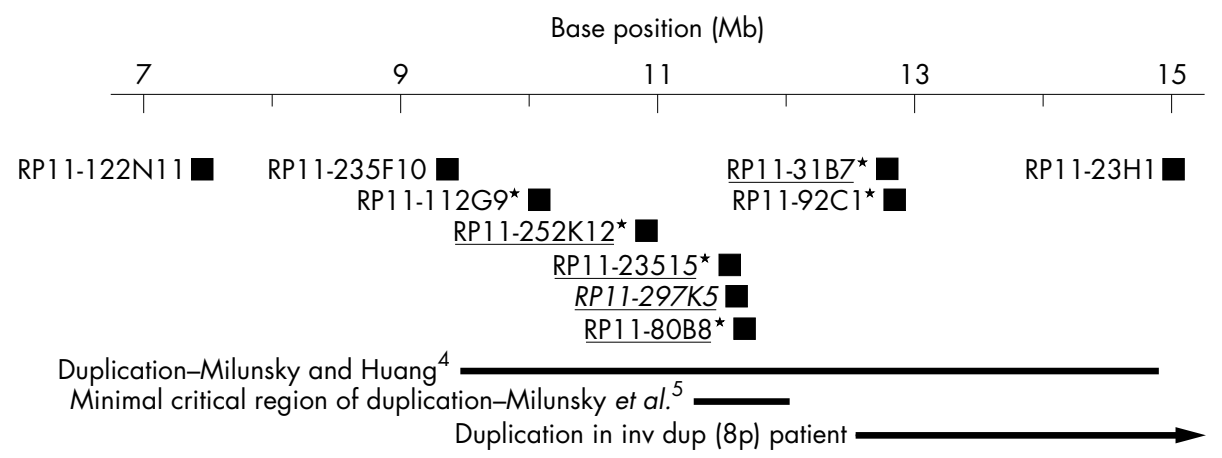

Figure 2 Chromosome region 8p22-p23.1. Genomic positions of BAC clones are indicated (UCSC Genome Browser). Starred clones were reported as duplicated by Milunsky et al, ${ }^{4}$ and clones RP1 1-235F10 and RP1 1-23H1 were reported as normal. ${ }^{4}$ Underlined clones were used for fluorescence in situ hybridisation in this paper; the italicised clone (RP1 1-297K5) was on the aCGH array. The maximum size of the 8p duplication as reported by Milunsky and Huang ${ }^{4}$ is indicated. The approximate location of the minimal critical region as reported by Milunsky et a $\beta^{5}$ is denoted. The extent of the duplication in the inv dup (8p) patient used as a control is indicated by the line with the arrowhead, with the arrowhead signifying that the duplication extends further toward the centromere. 


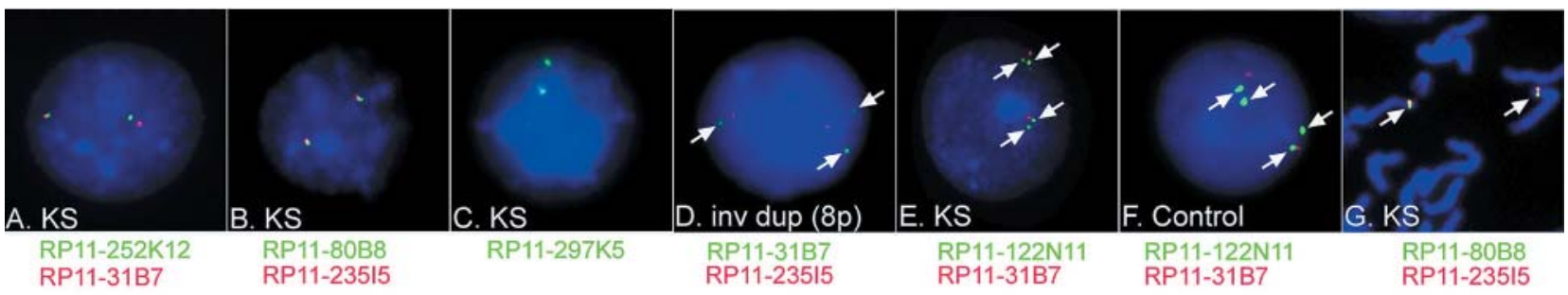

Figure 3 Fluorescence in situ hybridisation of 8p22-p23.1. BAC clones mapping to 8p22-8p23.1 served as the template for fluorescently labelled probes. Only two signals were observed in the subjects with Kabuki syndrome for each of the clones: RP1 1-252K12 (A), RP1 1-31B7 (A), RP1 1-23515 (B), and RP11-80B8 (B). In addition, the clone RP11-297K5, which maps to the reported minimal critical region, also showed two signals in cases of Kabuki syndrome (C). In the Kabuki syndrome cases, only two signals for each of the clones listed in table 1 were also observed in analysis of metaphase spreads, as shown in the representative partial metaphase spread depicted of clones RP1 1-80B8 and RP1 1-235I5 (G). In the case with the inv dup (8p), RP1 1-31B7 showed three signals (D), consistent with the known duplication in this positive control. The clone RP11-122N11 showed four signals in samples from both Kabuki syndrome cases (E) and unaffected subjects (F).

FISH analysis of chromosome region 8 p22-8p23.1 Material suitable for FISH was available in 11 of the 15 subjects. The BAC probes RP11-252K12, RP11-31B7, RP11235I5, and RP11-80B8 were used for FISH analysis in these 11 confirmed cases of Kabuki syndrome. At least 30 interphase nuclei were examined for each probe used for each patient. FISH analysis showed that each of the four BACs had only two signals, not the three that would have been expected if a duplication were present on one chromosome 8 homolog (fig 3A, B; table 2). At least 10 metaphase spreads were also examined for each probe used for each patient, and no duplications were detected.

In order to ensure that a duplication could be readily detected, we used as a positive control a sample obtained from a subject who does not have Kabuki syndrome but who has an inverted duplication of 8p (inv dup (8p)) (karyotype $46, X Y$,del $\operatorname{dup}(8)($ qter $\rightarrow$ p23.1 ::p23.1 $\rightarrow$ pl 1.2)). This inverted duplication has been described in several individuals who do not have Kabuki syndrome and is associated with a distinct clinical phenotype that is clearly different from Kabuki syndrome. These individuals also have a deletion that involves the $8 \mathrm{p}$ subtelomeric region. The duplicated region in the inv dup ( $8 \mathrm{p}$ ) partially overlaps but is different from the $8 p$ duplication reported in cases of Kabuki syndrome ${ }^{10}{ }^{11}$ (fig 2). Based on the karyotype and reports of other reported inv dup (8p) cases, it would be expected that the duplicated material includes $8 \mathrm{p} 22$ and a variable amount of $8 \mathrm{p}$ material centromeric to genomic position $12.58 \mathrm{Mb}$ on $8 \mathrm{p} 22 .{ }^{11}{ }^{12}$ The BAC RP11-31B7 maps to the duplicated region and thus was expected to be duplicated in this subject. In fact, the RPI1$31 \mathrm{~B} 7$ clone showed three signals in interphase nuclei in this positive control sample (fig 3D), consistent with a duplication of $8 \mathrm{p} 22$ on one of the chromosome 8 homologs. As expected, FISH with BACs RP11-252K12 and RP11-235I5 showed two signals in this case (table 2), as these BACs do not map to the duplicated region in the inv dup (8p) (fig 2). These data indicate that FISH analysis in our laboratory can detect a duplication of $8 \mathrm{p} 22$, if present.

\section{FISH analysis with the BAC RP11-122N11}

In the published report on the $8 \mathrm{p}$ duplication in Kabuki syndrome, ${ }^{4}$ the BAC RP11-122N1l lies outside of the duplicated region. However, it was reported to show three signals in interphase nuclei, and this was interpreted as an inversion. ${ }^{4}$ We undertook FISH analysis with this BAC to assess the hybridisation pattern with this clone. FISH analysis with this probe showed four signals in the cases with Kabuki syndrome that we studied (fig 3E, table 1). In order to determine the FISH pattern in individuals without Kabuki syndrome, we also carried out FISH with BAC RP11$122 \mathrm{~N} 11$ on two samples from unaffected subjects who were not related to a person with Kabuki syndrome. Of note, a

\begin{tabular}{|c|c|c|c|c|c|c|c|}
\hline \multirow[b]{2}{*}{ Patient } & \multirow[b]{2}{*}{ Diagnosis } & \multicolumn{5}{|l|}{ FISH } & \multirow{2}{*}{$\begin{array}{l}\text { aCGH } \\
\text { RP11- } \\
297 \text { K5 }\end{array}$} \\
\hline & & RP11-252K12 & RP1 1-23515 & RP11-80B8 & RP11-31B7 & $\begin{array}{l}\text { RP11- } \\
\text { 122N11 }\end{array}$ & \\
\hline 1 & KS & 2 & 2 & 2 & 2 & - & 2 \\
\hline 2 & KS & 2 & 2 & 2 & 2 & 4 & - \\
\hline 3 & KS & 2 & 2 & 2 & 2 & 4 & 2 \\
\hline 4 & KS & 2 & 2 & 2 & 2 & - & 2 \\
\hline 5 & KS & 2 & 2 & 2 & 2 & - & 2 \\
\hline 6 & KS & 2 & 2 & 2 & 2 & - & 2 \\
\hline 7 & KS & 2 & 2 & 2 & 2 & 4 & 2 \\
\hline 8 & KS & 2 & 2 & 2 & 2 & 4 & - \\
\hline 9 & KS & 2 & 2 & 2 & 2 & 4 & - \\
\hline 10 & KS & 2 & 2 & 2 & 2 & - & - \\
\hline 11 & KS & 2 & 2 & 2 & 2 & - & - \\
\hline 12 & KS & - & - & - & - & - & 2 \\
\hline 13 & KS & - & - & - & - & - & 2 \\
\hline 14 & KS & - & - & - & - & - & 2 \\
\hline 15 & KS & - & - & - & - & - & 2 \\
\hline 16 & Inv dup (8p) & 2 & 2 & - & 3 & - & - \\
\hline 17 & Control & - & - & - & - & 4 & - \\
\hline 18 & Control & - & - & - & - & 4 & - \\
\hline
\end{tabular}


similar pattern of four FISH signals was detected in the two unaffected controls as well (fig 3F). This indicates that the four signals of the RPl1-122N11 probe are present in the general population, suggesting that chromosome specific, low copy repeats may be present on $8 \mathrm{p}$.

\section{aCGH analysis of the $8 p 22-8 p 23.1$ region}

For six of the 11 Kabuki syndrome cases studied by FISH, as well as four additional cases ( 10 of the total cohort of 15), we also used array based comparative genomic hybridisation (aCGH) as an independent method to test for an $8 p$ duplication. This array can readily and reliably detect single copy changes in genome dosage. ${ }^{913}$ The array contains the BAC clone RP11-297K5 (11.57-11.74 Mb, UCSC Genome Browser), which lies within the reported minimal duplicated region. ${ }^{5}$ In aCGH, the test and control genomic DNA samples are labelled with either $\mathrm{Cy} 3$ or $\mathrm{Cy} 5$, respectively. The relative intensity ratio of the signal from these dyes (Cy3:Cy5 ratio) indicates the relative copy number of a given chromosomal region. In the aCGH studies with our cohort, the Cy3:Cy5 ratio for RP11-297K5 did not vary significantly from the normal ratio of 1.0 (normal range 0.8 to 1.2 ) in any of the 10 Kabuki syndrome cases, indicating that the copy number was normal (table 2). We also used this clone as a FISH probe and did not detect a duplication of this BAC by this method (fig 3C). Thus the aCGH studies did not identify a duplication of $8 p$ in the subjects examined.

\section{DISCUSSION}

Milunsky et al described a duplication of 8p22-8p23.1 ranging between 0.83 and $3.5 \mathrm{Mb}$ in all 13 cases of Kabuki syndrome whom they studied. ${ }^{4}$ We used two independent platforms to assess for this duplication: aCGH and FISH. In contrast to the reported findings, we failed to detect the reported 8p22-p23.1 duplication in any of a cohort of 15 cases of Kabuki syndrome that we studied by FISH, aCGH, or both. Our data indicate that an $8 p$ duplication was not present in this set of patients. This suggests that the $8 \mathrm{p}$ duplication may not be a common finding in Kabuki syndrome. Of note, a recent study described FISH analysis of 26 Japanese and two Thai cases with typical features of Kabuki syndrome, and this study also failed to detect the reported 8p22-p23.1 duplication. ${ }^{14}$

In the report of the 8p duplication, ${ }^{4}$ the clone RP11-122N I 1 was found to give three FISH signals in the cases of Kabuki syndrome and their mothers. We found that the BAC clone RP11-122N11 gave four signals in interphase FISH analysis both in the Kabuki syndrome cases and in unaffected controls. Of note, this BAC contains segmental duplication sequences, based on the UCSC Genome Browser (April 2003 freeze). The RP11-122N11 clone has only been mapped by FISH (UCSC Genome Browser), and the precise genomic location of this clone has not been unequivocally determined. Thus it is possible that this clone hybridises to low copy repeat sequences that are present in more than one region of the chromosome. Alternatively, duplications of the genomic sequence corresponding to this clone may be present in the general population, as four hybridisation signals were also seen in samples from unaffected individuals who were not related to a person with Kabuki syndrome. The genomic organisation of $8 \mathrm{p} 22-\mathrm{p} 23.1$ is quite complex, with several low copy repeat elements, and the finding of multiple signals of RPll-122N1l is a reflection of the complexity of the underlying genomic structure.

The reason for the discrepancy between our findings and those of Milunsky and Huang ${ }^{4}$ is not clear at present. The cases studied in our cohort had facial features that were characteristic of Kabuki syndrome, including long eyelashes, eversion of the lower lateral eyelid, anomalous eyebrows, and a depressed nasal tip. It is possible that there are clinical differences between the subjects described with the duplication and those in our cohort. The cases in whom the 8p duplication was detected ${ }^{4}$ may represent a clinical subset. The presence of segmental duplications in the 8p22-p23.1 region may also complicate FISH analysis if the BAC clones used for FISH contain these repeat sequences. In addition, FISH may be susceptible to experimental artefacts owing to asynchronous replication of the chromosomal homologs, differences in BAC preparation, or other factors that could lead to the discrepant findings. Further investigations into the aetiology of Kabuki syndrome will be required to determine the predominant genetic cause of this condition.

\section{ACKNOWLEDGEMENTS}

We thank Sonya Babar for technical assistance. We thank the families and the Kabuki Syndrome Network for their participation. This work was supported in part by funding from the Penn Genomics Institute (to JEM) and from the Abramson Family Cancer Research Institute (to BLW). Support was also provided from the Mental Retardation and Developmental Disabilities Research Center at the Children's Hospital of Philadelphia (NIH grant HD26979).

\section{Authors' affiliations}

J D Hoffman, Y Zhang, K L Ciprero, B S Emanuel, E H Zackai, J E Ming, Division of Human Genetics, Department of Pediatrics, The Children's Hospital of Philadelphia and The University of Pennsylvania School of Medicine, Philadelphia, Pennsylvania, USA

J Greshock, B L Weber, Abramson Family Cancer Research Institute, The University of Pennsylvania

Competing interests: none declared

Correspondence to: Dr Jeffrey E Ming, The Children's Hospital of Philadelphia, Abramson Research Building, Room 1002, 3615 Civic Center Boulevard, Philadelphia, PA 19104, USA; jeming@mail.med. upenn.edu

\section{REFERENCES}

1 Niikawa N, Matsuura N, Fukushima Y, Ohsawa T, Kajii T. Kabuki make-up syndrome: a syndrome of mental retardation, unusual facies, large and protruding ears, and postnatal growth deficiency. J Pediatr 1981;99:565-9.

2 Kuroki Y, Suzuki Y, Chyo H, Hata A, Matsui I. A new malformation syndrome of long palpebral fissures, large ears, depressed nasal tip, and skeletal anomalies associated with postnatal dwarfism and mental retardation. J Pediatr 1981;99:570-3.

3 Matsumoto N, Niikawa N. Kabuki make-up syndrome: a review. Am J Med Genet 2003;117C:57-65.

4 Milunsky JM, Huang XL. Unmasking Kabuki syndrome: chromosome 8p228 23. 1 duplication revealed by comparative genomic hybridization and BACFISH. Clin Genet 2003;64:509-16.

5 Milunsky JM, Maher TA, Huang XL. Refinement of the Kabuki syndrome critical region. American College of Medical Genetics, Annual Clinical Genetics Meeting, Kissimmee, FL, 2004; http://www.spltrak.com/ACMG/ CategoryAbstracts/cat3.html.

6 Ming JE, Russell KL, Bason L, McDonald-McGinn DM, Zackai EH. Coloboma and other ophthalmologic anomalies in Kabuki syndrome: distinction from CHARGE association. Am J Med Genet 2003;123A:249-52.

7 Ming JE, Russell KL, McDonald-McGinn DM, Zackai EH. Autoimmune disease in Kabuki syndrome. Am J Med Genet (in press).

8 Shaikh TH, Kurahashi H, Saitta SC, O'Hare AM, Hu P, Roe BA, Driscoll DA, McDonald-McGinn DM, Zackai EH, Budarf ML, Emanuel BS. Chromosome 22 -specific low copy repeats and the 22q 11.2 deletion syndrome: genomic organization and deletion endpoint analysis. Hum Mol Genet 2000;9:489-501.

9 Greshock J, Naylor TL, Margolin A, Diskin S, Cleaver SH, Futreal PA, DeJong PJ, Zhao S, Liebman M, Weber BL. 1-Mb resolution array-based comparative genomic hybridization using a BAC clone set optimized for cancer gene analysis. Genome Res 2004;14:179-87.

10 Floridia G, Piantanida M, Minelli A, Dellavecchia C, Bonaglia C, Rossi E, Gimelli G, Croci G, Franchi F, Gilgenkrantz S, Grammatico P, Dalpra L, Wood S, Danesino C, Zuffardi O. The same molecular mechanism at the maternal meiosis I produces mono- and dicentric $8 p$ duplications. Am J Hum Genet 1996;58:785-96.

11 Giglio S, Broman KW, Matsumoto N, Calvari V, Gimelli G, Neumann T, Ohashi H, Voullaire L, Larizza D, Giorda R, Weber JL, Ledbetter DH, Zuffardi $O$. Olfactory receptor-gene clusters, genomic-inversion polymorphisms, and common chromosome rearrangements. Am J Hum Genet 2001;68:874-83.

12 Sugawara H, Harada N, Ida T, Ishida T, Ledbetter DH, Yoshiura K, Ohta T, Kishino T, Niikawa N, Matsumoto N. Complex low-copy repeats associated 
with a common polymorphic inversion at human chromosome $8 \mathrm{p} 23$. Genomics 2003;82:238-44.

13 Mosse Y, Greshock J, King A, Khazi D, Weber BL, Maris JM. Identification and high-resolution mapping of a constitutional $11 \mathrm{q}$ deletion in an infant with multifocal neuroblastoma. Lancet Oncol 2003;4:769-71.
14 Miyake N, Harada N, Shimokawa O, Ohashi H, Kurosawa K, Matsumoto T, Fukushima Y, Nagai T, Shotelersuk V, Yoshiura K, Ohta T, Kishino T, Niikawa N, Matsumoto N. On the reported 8p22-p23. 1 duplication in Kabuki make-up syndrome (KMS) and its absence in patients with typical KMS. Am J Med Genet 2004;128A:170-2.

\section{Clinical Evidence - Call for contributors}

Clinical Evidence is a regularly updated evidence-based journal available worldwide both as a paper version and on the internet. Clinical Evidence needs to recruit a number of new contributors. Contributors are healthcare professionals or epidemiologists with experience in evidence-based medicine and the ability to write in a concise and structured way.

Areas for which we are currently seeking authors:

- Child health: nocturnal enuresis

- Eye disorders: bacterial conjunctivitis

- Male health: prostate cancer (metastatic)

- Women's health: pre-menstrual syndrome; pyelonephritis in non-pregnant women

However, we are always looking for others, so do not let this list discourage you.

Being a contributor involves:

- Selecting from a validated, screened search (performed by in-house Information Specialists) epidemiologically sound studies for inclusion.

- Documenting your decisions about which studies to include on an inclusion and exclusion form, which we keep on file.

- Writing the text to a highly structured template (about 1500-3000 words), using evidence from the final studies chosen, within 8-10 weeks of receiving the literature search.

- Working with Clinical Evidence editors to ensure that the final text meets epidemiological and style standards.

- Updating the text every six months using any new, sound evidence that becomes available. The Clinical Evidence in-house team will conduct the searches for contributors; your task is simply to filter out high quality studies and incorporate them in the existing text.

- To expand the topic to include a new question about once every 12-18 months.

If you would like to become a contributor for Clinical Evidence or require more information about what this involves please send your contact details and a copy of your CV, clearly stating the clinical area you are interested in, to Klara Brunnhuber (kbrunnhuber@ bmigroup.com).

\section{Call for peer reviewers}

Clinical Evidence also needs to recruit a number of new peer reviewers specifically with an interest in the clinical areas stated above, and also others related to general practice. Peer reviewers are healthcare professionals or epidemiologists with experience in evidence-based medicine. As a peer reviewer you would be asked for your views on the clinical relevance, validity, and accessibility of specific topics within the journal, and their usefulness to the intended audience (international generalists and healthcare professionals, possibly with limited statistical knowledge). Topics are usually 1500-3000 words in length and we would ask you to review between 2-5 topics per year. The peer review process takes place throughout the year, and our turnaround time for each review is ideally 10-14 days.

If you are interested in becoming a peer reviewer for Clinical Evidence, please complete the peer review questionnaire at www. clinicalevidence.com or contact Klara Brunnhuber (kbrunnhuber@bmigroup.com). 